\title{
The increasing impact of lethal mutagenesis of viruses
}

\author{
Celia Perales*,1,2,3, Isabel Gallego 2,3 , Ana Isabel de Ávila ${ }^{3}$, María Eugenia Soria ${ }^{3}$, Josep \\ Gregori ${ }^{2,4,5}$, Josep Quer ${ }^{2,4,6}$ \& Esteban Domingo ${ }^{2,3}$ \\ ${ }^{1}$ Department of Clinical Microbiology, IIS-Fundación Jiménez Díaz, UAM. Av. Reyes Católicos 2, 28040, Madrid, Spain \\ ${ }^{2}$ Centro de Investigación Biomédica en Red de Enfermedades Hepáticas y Digestivas (CIBERehd) del Instituto de Salud Carlos III, \\ 28029, Madrid, Spain \\ ${ }^{3}$ Centro de Biología Molecular 'Severo Ochoa' (CSIC-UAM), Consejo Superior de Investigaciones Científicas (CSIC), Campus de \\ Cantoblanco, 28049, Madrid, Spain \\ ${ }^{4}$ Liver Unit, Internal Medicine Hospital Universitari Vall d'Hebron, Vall d'Hebron Institut de Recerca (VHIR), Barcelona, Spain \\ ${ }^{5}$ Roche Diagnostics, S.L., Sant Cugat del Vallés, 08174, Barcelona, Spain \\ ${ }^{6}$ Universitat Autónoma deBarcelona, 08193, Barcelona, Spain \\ *Author for correspondence: cperales@cbm.csic.es
}

Selection of viral mutants resistant to compounds used in therapy is a major determinant of treatment failure, a problem akin to antibiotic resistance in bacteria. In this scenario, mutagenic base and nucleoside analogs have entered the picture because they increase the mutation rate of viral populations to levels incompatible with their survival. This antiviral strategy is termed lethal mutagenesis. It has found a major impulse with the observation that some antiviral agents, which initially were considered only inhibitors of virus multiplication, may in effect exert part of their antiviral activity through mutagenesis. Here, we review the conceptual basis of lethal mutagenesis, the evidence of virus extinction through mutagenic nucleotide analogs and prospects for application in antiviral designs.

First draft submitted: 11 September 2018; Accepted for publication: 21 March 2019; Published online: 30 August 2019

Keywords: antiviral drugs • error catastrophe • viral quasispecies

The prevention and treatment of diseases associated with RNA viruses is based on two major strategies: vaccination and pharmacological intervention. Both have met with considerable difficulties derived mainly from the still limited knowledge of the basis of protective responses evoked by vaccines, and underestimation of the capacity of viral populations to overcome immune responses and inhibitory activities. In the case of antiviral inhibitors, two main factors intervene: the selection of inhibitor-resistant viral mutants while viruses replicate in the infected host subjected to treatment, and the increase at the epidemiological level of circulating viruses that harbor resistance mutations. The basal level of resistance mutations varies greatly among different pathogens, but it may diminish the efficacy of an initial treatment. The challenge of avoiding escape mutants has been responded to in clinical practice with a deeper characterization of viral populations prior to treatment onset, and the use of combination therapies that for statistical reasons render selection of escape mutants a far less frequent event than with monotherapy. Nevertheless, the problem is far from being solved, and its roots lie in the capacity of RNA virus populations to respond to changing environments such as the introduction of antiviral inhibitors during their replication.

Because of their being general features of RNA viruses, high mutation rates and the generation of mutant swarms demand new disease control strategies [1-6]. An approach with a mounting impact in antiviral research consists in driving viral populations toward nonfunctionality by an increase of the average mutation rate. This strategy is known as lethal mutagenesis or transition into error catastrophe. Error catastrophe was initially used to describe deterioration of cellular functions as a hypothesis for the process of aging [7]. Subsequently, it was adopted in quasispecies theory to refer to a critical transition from organized distribution of genomes (dominated by one or several 'master' sequences) toward a collection of genomes that, devoid of a master sequence, drift in sequence space. Quasispecies theory was developed by Eigen and Schuster to describe quantitatively genome replication with production of error copies, as a step in self-organization of simple replicons at the origin of life [8]. Despite different 
views on the mechanism of virus extinction by excess mutations, quasispecies theory was at the inception of the experiments that opened the way to this new antiviral strategy $[5,9,10]$.

The term lethal mutagenesis was coined by Loeb et al. who documented the adverse effect of the pyrimidine analog 5-hydroxydeoxycytidine on HIV-1 replication [9]. The introduction of excess mutations in viral genomes is often achieved with base and nucleoside analogs that display acceptable levels of toxicity for host cells and organisms. They are intracellularly converted into their active nucleotide forms. The latter can take the place of standard nucleotides, and be ambiguously incorporated opposite to any of the two complementary purine or pyrimidine template residues. Once incorporated, they induce misincorporations acting as template residues during the following replication rounds. Some mutagenic analogs can also produce RNA chain termination, although compounds whose mechanism of action is limited to RNA chain termination constitute a different group of antiviral agents [11]. The molecular basis of mutagenesis by nucleotide analogs is only partially understood but it likely comprises base mispairing through hydrogen bonds that differ in location and strength from those that dictate the standard Watson-Crick or wobble base pairs.

Lethal mutagenesis is an expanding chapter of antiviral pharmacology due to the impulse of theoretical and experimental studies, together with the finding that some antiviral inhibitors that were licensed for administration to humans as inhibitors of viral replication may actually exert their antiviral activity partly through mutagenesis. The classical example is ribavirin (1- $\beta$-D-ribofuranosyl-1- $H-1,2,4$-triazole-3-carboxamide), a purine analog used as antiviral agent since the 1970s that displays multiple mechanisms of activity, such as depletion of GTP levels through inhibition of cellular inosine-monophosphate dehydrogenase by its mononucleotide derivative ribavirinmonophosphate, enhancement of the antiviral Th1 immune response, inhibition of mRNA cap formation and direct inhibition of viral RNA-dependent RNA polymerase [12]. Ribavirin was first shown to be mutagenic for poliovirus [13], and then for several RNA viruses [12]. Ribavirin and other base and nucleoside analogs, some used in cancer chemotherapy (e.g., 5-fluorouracil or 5-azacytidine), have contributed to the development of lethal mutagenesis (Table 1).

Favipiravir (T-705; 6-fluoro-3-hydroxy-2-pirazinecarboxamide), another purine analog introduced more recently as antiviral agent [14], has followed a similar course of events. It was shown to be an inhibitor of influenza virus RNA replication, with an RNA chain termination activity $[15,16]$, and some key residues of the polymerase of positivesense single-stranded RNA viruses identified as determinant of its broad-spectrum antiviral activity [17]. Favipiravir is approved as an anti-influenza virus agent in Japan. It was later proven mutagenic for influenza virus [18], and then for several additional RNA viruses in cell culture and in vivo (Table 2). Particularly noteworthy is the evidence that protective favipiravir doses against Ebola virus infection in macaques were associated with mutagenesis [19].

Many studies with different viruses and mutagenic agents have confirmed that RNA viruses can be extinguished by increasing their mutation rate during replication, with consistent outcomes with viruses that use different replication mechanisms (Tables $1 \& 2$ ).

\section{Multiple questions \& models, but one outcome}

As it sometimes happens in science, once lethal mutagenesis was perceived as a potential antiviral strategy, its conceptual foundations became of interest to experts in widely different disciplines who proposed different interpretations. This did not come as a surprise given its origins in quasispecies theory, connections with population genetics and implications for antiviral pharmacology, with its commercial connotations. In addition to its molecular basis, the antiviral activity of nucleotide analogs has raised several questions that are currently under investigation: Is the mutagenic activity the direct cause of virus extinction? When an analog targets the RNA-dependent RNA polymerase (RdRp; not other cellular or viral functions), is the observed viral inhibition a consequence of mutagenesis or do mutagenic and inhibitory activities coexist independently? Do other base, nucleoside and nucleotide analogs used in antimicrobial or anticancer therapy have hitherto unrecognized mutagenic activities for RNA viruses? Some of these issues are discussed next, with an effort to reconcile theoretical proposals with experimental findings.

Extended Darwinian dynamics, which captures processes of mutant generation, competition and selection has had different mathematical formulations in history. Since the different equations that describe such formulations are related [20], the question is why was quasispecies the framework adopted to explain RNA virus behavior at the population level. A convincing reason is that the fundamental equation that describes quasispecies dynamics quantifies the variation as a function of time of the concentration of individual genomes due to replication rate and the occurrence of mutations (from and toward any individual genome) (formulation summarized in [8], and 
Table 1. Summary of some studies on lethal mutagenesis of viruses by base and nucleoside analogs.

\begin{tabular}{|c|c|c|c|c|}
\hline Virus & Host & Drug and concentration range & Main observations & Ref. \\
\hline $\begin{array}{l}\text { VSV } \\
\text { PV }\end{array}$ & BHK-21, HeLa cells & $\begin{array}{l}\mathrm{FU}(1-200 \mu \mathrm{g} / \mathrm{ml}) \\
5-\mathrm{aza}-\mathrm{C}(1-10 \mu \mathrm{g} / \mathrm{ml})\end{array}$ & $\begin{array}{l}\text { Impairments of viral replication; } 16 \text { - to } 2.8 \text {-fold increases in mutation } \\
\text { frequency }\end{array}$ & [10] \\
\hline VSV & BHK-21 cells & $\mathrm{FU}(3-400 \mu \mathrm{g} / \mathrm{ml})$ & Adverse effect of mutagenesis on virus viability and adaptability & [86] \\
\hline HIV-1 & CEM cells & $5-\mathrm{OH}-\mathrm{dc}(1000 \mu \mathrm{M})$ & $\begin{array}{l}\text { Decrease of virus infectivity; threefold increase of mutation frequency } \\
\text { and } 5.6 \text {-fold increase in } G \rightarrow A \text { transitions }\end{array}$ & [9] \\
\hline FMDV & BHK-21 cells & $\begin{array}{l}\text { FU }(10-1000 \mu \mathrm{g} / \mathrm{ml}) \\
5-a z a-C(5-10 \mu \mathrm{g} / \mathrm{ml})\end{array}$ & $\begin{array}{l}\text { Decrease of virus infectivity; fitness and viral load-dependent } \\
\text { extinction. 2- to } 6.4 \text {-fold increase in mutation frequency }\end{array}$ & [23] \\
\hline FMDV & BHK-21 cells & $\mathrm{FU}(200 \mu \mathrm{g} / \mathrm{ml})$ & $\begin{array}{l}\text { Virus extinction by FU in combination with the nonmutagenic } \\
\text { inhibitors guanidine hydrochloride and heparin Requirement of drug } \\
\text { combination to extinguish high fitness FMDV }\end{array}$ & [43] \\
\hline PV & HeLa cells & RBV $(100-1000 \mu M)$ & $99.3 \%$ loss of genome infectivity with 9.7 -fold increase in mutagenesis & [87] \\
\hline LCMV & BHK-21 cells & $\begin{array}{l}\text { FU }(10-100 \mu \mathrm{g} / \mathrm{ml}) \\
5-a z a-C(5-10 \mu \mathrm{g} / \mathrm{ml})\end{array}$ & $\begin{array}{l}\text { Virus extinction; largest increases in mutation frequency did not } \\
\text { predict extinction }\end{array}$ & [57] \\
\hline FMDV & BHK-21 cells & RBV $(100-500 \mu \mathrm{M})$ & $\begin{array}{l}\text { Curing of virus from persistently infected cells, associated with up to } \\
\text { tenfold increase of mutation frequency }\end{array}$ & [88] \\
\hline FMDV & BHK-21 cells & $\mathrm{FU}(100-200 \mu \mathrm{g} / \mathrm{ml})$ & $\begin{array}{l}\text { Virus extinction required mutagenesis and not only inhibition by } \\
\text { guanidine hydrochloride and heparin }\end{array}$ & [26] \\
\hline LCMV & BHK-21 cells & $\begin{array}{l}\text { FU }(50-800 \mu \mathrm{g} / \mathrm{ml}) \\
\text { RBV }(100-400 \mu \mathrm{M})\end{array}$ & $\begin{array}{l}\text { FU- and RBV-mediated extinction of LCMV in BHK- } 21 \text { cells, associated } \\
\text { with up to tenfold increases of mutation frequency with FU and } \\
\text { inhibition of gene expression with RBV }\end{array}$ & [60] \\
\hline HTNV & Vero E6 cells & $\mathrm{RBV}(12 \mu \mathrm{g} / \mathrm{ml})$ & $\begin{array}{l}\text { Adverse effect of RBV on HTNV gene expression and progeny } \\
\text { production; 8.7-fold increase of mutation frequency in S-RNA }\end{array}$ & [89] \\
\hline WNV & $\begin{array}{l}\text { HeLa, CV-1, L929, Vero, } \\
\text { MA-104 cells }\end{array}$ & RBV $(100 \mu \mathrm{g} / \mathrm{ml})$ & $\begin{array}{l}\text { Evidence of RBV-mediated extinction of WNV in HeLa (but not other } \\
\text { cell types) associated with increased mutation frequency and } \\
\text { decreased specific infectivity }\end{array}$ & {$[90]$} \\
\hline HIV-1 & PBMCs, MT-4 cells & 5-OH-dC (2 mM) & $\begin{array}{l}\text { Efficient HIV-1 extinction by combinations of } 5-\mathrm{OH}-\mathrm{dc} \text { and } \\
3^{\prime} \text {-azido-3'-deoxythymidine (AZT) }\end{array}$ & [44] \\
\hline HIV-1 & $\begin{array}{l}\text { U373-MAGI } \\
\text { cells }\end{array}$ & 5-aza-dC (10 nM-1 mM) & $\begin{array}{l}\text { Adverse effect of 5-aza-dC on HIV-1 infectivity, with its principal } \\
\text { mechanism being incorporation during reverse transcription }\end{array}$ & [91] \\
\hline FMDV & BHK-21 cells & $\mathrm{FU}(200-500 \mu \mathrm{g} / \mathrm{ml})$ & $\begin{array}{l}\text { Extinction of a RBV-resistant mutant by combination of FU and } \\
\text { guanidine hydrochloride }\end{array}$ & [92] \\
\hline LCMV & BHK-21 cells & $\operatorname{RBV}(20-100 \mu \mathrm{M})$ & $\begin{array}{l}\text { RBV subinhibitory concentrations exerted mutagenic activity through } \\
\text { an increase of mutant spectrum complexity, decrease of specific } \\
\text { infectivity and increase of } G \rightarrow A, C \rightarrow U \text { transitions }\end{array}$ & {$[61]$} \\
\hline HIV-1 & U373-MAGI ${ }_{C X C R 4}$ & 5-aza-dC (10-200 $\mu \mathrm{M})$ & $\begin{array}{l}\text { Adverse effect of 5-aza-dC on viral infectivity, potentiated by the host } \\
\text { factor APOBEC3G }\end{array}$ & [93] \\
\hline $\mathrm{HCV}$ & Huh-7.5 cells & RBV $(50-100 \mu \mathrm{M})$ & $\begin{array}{l}\text { RBV-mediated extinction of HCV through an increase of mutant } \\
\text { spectrum complexity and decrease of specific infectivity }\end{array}$ & [94] \\
\hline TMV & N. tabacum & FU (up to $100 \mu \mathrm{g} / \mathrm{ml}$ ) & $\begin{array}{l}\text { FU-mediated decrease of TMV infectivity and increase of } A \rightarrow G, U \rightarrow C \\
\text { transitions }\end{array}$ & [30] \\
\hline \multicolumn{5}{|c|}{ 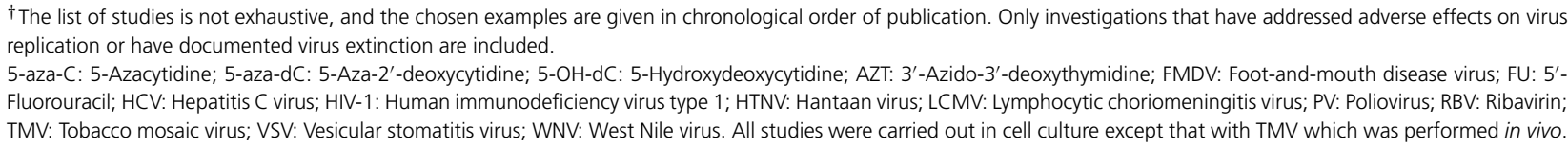 } \\
\hline
\end{tabular}

explained in the context of RNA viral evolution in [3]). The parallelism between the processes of mutation and correct replication distinguishes quasispecies from other Darwinian formulations [20].

The consideration of mutation as inherent to replication underlies the error threshold relationship of quasispecies theory [21,22] that predicts loss of inheritable information when error rates exceed a threshold value. The error threshold value is determined by the complexity of the information to be transmitted (equated with genome size, provided redundant information is absent), and by the degree of adaptation of the replicating ensemble to the environment (quantified by the fitness superiority of the dominant or master sequence or sequences over the surrounding mutant spectrum) [8,22]. This general prediction applies to all replicative entities, and, importantly, it was experimentally verified with RNA viruses, and it is also amenable to investigations with other RNA genetic elements and DNA viruses or replicons that display high basal average mutation rates. The usual range of mutation rates in these subcellular entities is $10^{-3}$ to $10^{-5}$ substitutions per nucleotide [5]. Copying fidelity is restricted by 


\begin{tabular}{|c|c|c|c|c|c|c|c|}
\hline Virus & Type of study & Host & $\begin{array}{l}\text { Concentration } \\
\text { range tested }\end{array}$ & Mutational effect & $\begin{array}{l}\text { Mutant type preference in } \\
\text { treated populations }\end{array}$ & Specific infectivity & Ref. \\
\hline IV & Cell culture & MDCK cells & $0.5-16 \mu \mathrm{M}$ & $\sim 3.35$-fold increase & $\begin{array}{l}\text { Bias in favor of } \mathrm{G} \rightarrow \mathrm{U} \text { and } \\
\mathrm{C} \rightarrow \mathrm{U}\end{array}$ & $\sim 25$-fold decrease & [18] \\
\hline MNV & Cell culture & RAW264.7 cells & $200-800 \mu \mathrm{M}$ & $\begin{array}{l}\text { Five- to sixfold } \\
\text { increase }\end{array}$ & $\begin{array}{l}\text { Bias in favor of } A \rightarrow G \text { and } \\
U \rightarrow C\end{array}$ & $\begin{array}{l}\sim 100 \text {-fold to } \\
1000 \text {-fold decrease }\end{array}$ & [65] \\
\hline MNV & In vivo & C57BL/6 mice & 600 mg/kg per day & $\sim 2.9$-fold increase & n.s. & $\sim$ Tenfold decrease & [65] \\
\hline $\mathrm{HCV}$ & Cell culture & Huh- 7.5 cells & $100-400 \mu \mathrm{M}$ & $\begin{array}{l}\sim \text { Two to fivefold } \\
\text { increase }\end{array}$ & $\begin{array}{l}\text { Bias in favor of } \mathrm{G} \rightarrow \mathrm{A} \text { and } \\
\mathrm{C} \rightarrow \mathrm{U}\end{array}$ & $\begin{array}{l}13 \text { - to } 20 \text {-fold } \\
\text { decrease }\end{array}$ & [95] \\
\hline FMDV & Cell culture & BHK-21 cells & $100-400 \mu \mathrm{M}$ & $\sim$ Fourfold increase & $\begin{array}{l}\text { No obvious outstanding } \\
\text { mutation type }\end{array}$ & $\begin{array}{l}27 \text { - to } 135 \text {-fold } \\
\text { decrease }\end{array}$ & [69] \\
\hline WNV & Cell culture & Vero cells & $0.5-2 \mathrm{mM}$ & $\sim 5.6$-fold increase & $\begin{array}{l}\text { Bias in favor of } G \rightarrow A \text { and } \\
A \rightarrow G \text {, to a lesser extent } \\
U \rightarrow C\end{array}$ & $\begin{array}{l}26 \text { - to } 95 \text {-fold } \\
\text { decrease }\end{array}$ & [96] \\
\hline DENV & Cell culture & Huh-7 cells & $200-500 \mu \mathrm{M}$ & $\begin{array}{l}\sim \text { Two- to 33-fold } \\
\text { increase }\end{array}$ & Bias in favor of transitions & $\begin{array}{l}\sim \text { Sevenfold } \\
\text { decrease }\end{array}$ & [64] \\
\hline EBV & In vivo & Macaca fascicularis & $\begin{array}{l}100- \\
180 \mathrm{mg} / \mathrm{kg} / \text { twice a } \\
\text { day }\end{array}$ & $\begin{array}{l}\text { Increase of minority } \\
\text { mutations }\end{array}$ & $\begin{array}{l}\text { Bias in favor of } G \rightarrow A \text { and } \\
C \rightarrow U\end{array}$ & $\begin{array}{l}\text { Up to } 16 \text {-fold } \\
\text { decrease }\end{array}$ & [19] \\
\hline ZIKV & Cell culture & Vero cells & $100-800 \mu \mathrm{M}$ & $\sim$ Fourfold increase & $\begin{array}{l}\text { Bias in favor of } G \rightarrow A \text { and } \\
C \rightarrow U\end{array}$ & $\sim 30$-fold decrease & [97] \\
\hline IV & Cell culture & MDCK, $293 \mathrm{~T}$ cells & $1-100 \mu \mathrm{M}$ & $\begin{array}{l}\sim \text { Two- to } 13 \text {-fold } \\
\text { increase }\end{array}$ & $\begin{array}{l}\text { Bias in favor of } \mathrm{G} \rightarrow \mathrm{A} \text { and } \\
\mathrm{C} \rightarrow \mathrm{U}\end{array}$ & n.s. & [98] \\
\hline \multicolumn{8}{|c|}{$\begin{array}{l}\text { †The list of studies is not exhaustive, and the chosen examples are given in chronological order of publication. Only investigations that have addressed adverse effects on virus } \\
\text { replication or have documented virus extinction are included. } \\
\text { DENV: Dengue virus; EBV: Ebola virus; FMDV: Foot-and-mouth disease virus; HCV: Hepatitis C virus; IV: Influenza virus; MNV: Murine norovirus; n.s.: Not specified.; WNV: West } \\
\text { Nile virus; ZIKV: Zika virus. }\end{array}$} \\
\hline
\end{tabular}

the absence of proofreading-repair activities, and poor activity of additional cellular repair functions during RNA replication and retrotranscription. The experiments that originated lethal mutagenesis as we understand it today were designed to explore the prediction of the error threshold relationship regarding the adverse effects of increasing the mutation rate on virus genetic and functional stability $[9,10,23]$ (Figure 1). The results agreed with the prediction, and replication of RNA viruses was hampered by high mutation rates, and in several cases virus extinction was achieved (Table 1).

Some alternative models to the crossing of the error threshold for maintenance of inheritable information implied by quasispecies theory were proposed to explain virus extinction by artificially enhanced mutation rates (reviewed in [24]). Eventually, extinction of a microbial pathogen is always a demographic process in which the infection cannot be sustained [25]. The critical issue is what triggers the demographic event. At least with the picornavirus foot-andmouth disease virus (FMDV) under our cell culture conditions, mutagenesis was essential for loss of infectivity since equivalent inhibitory intensities achieved with nonmutagenic inhibitors did not result in virus extinction [26]. Additional studies (reviewed in [5]) suggest that a mutagenesis-driven movement of the virus population toward unfavorable regions of sequence space, in which defective genomes increase in frequency, may be key to virus extinction. This proposal is based on experimental results, together with theoretical studies performed by Manrubia and colleagues (several of them reviewed in $[3,5]$ ). Two steps were identified in the process of extinction that suggested a complex transition at the molecular level. In the first step, the mutant cloud distribution produced under the basal mutagenesis input typical of RNA viruses is first perturbed by enhanced mutagenesis, due to generation of defective genomes that interfere with replication of standard (still nonmutagenized or minimally mutagenized, nondefective) genomes. In our systems, this interference that we call lethal defection, by itself impeded progression of the infection, and led to virus extinction [27]. The occurrence of a lethal defection phase was experimentally supported by the fact that loss of infectivity preceded elimination of viral RNA [27], and by the presence in mutagenized viral populations of mutants that exerted an interfering activity [28,29]. The model has found also support in the antiviral activity of 5-fluorouracil (FU) on the plant virus tobacco mosaic virus [30], a study that has inaugurated lethal mutagenesis for plant viruses. It is interesting that a participation of defective genomes in virus extinction adds to evidence of the role of several classes of defective genomes, including defective-interfering particles, in various aspects of virus 


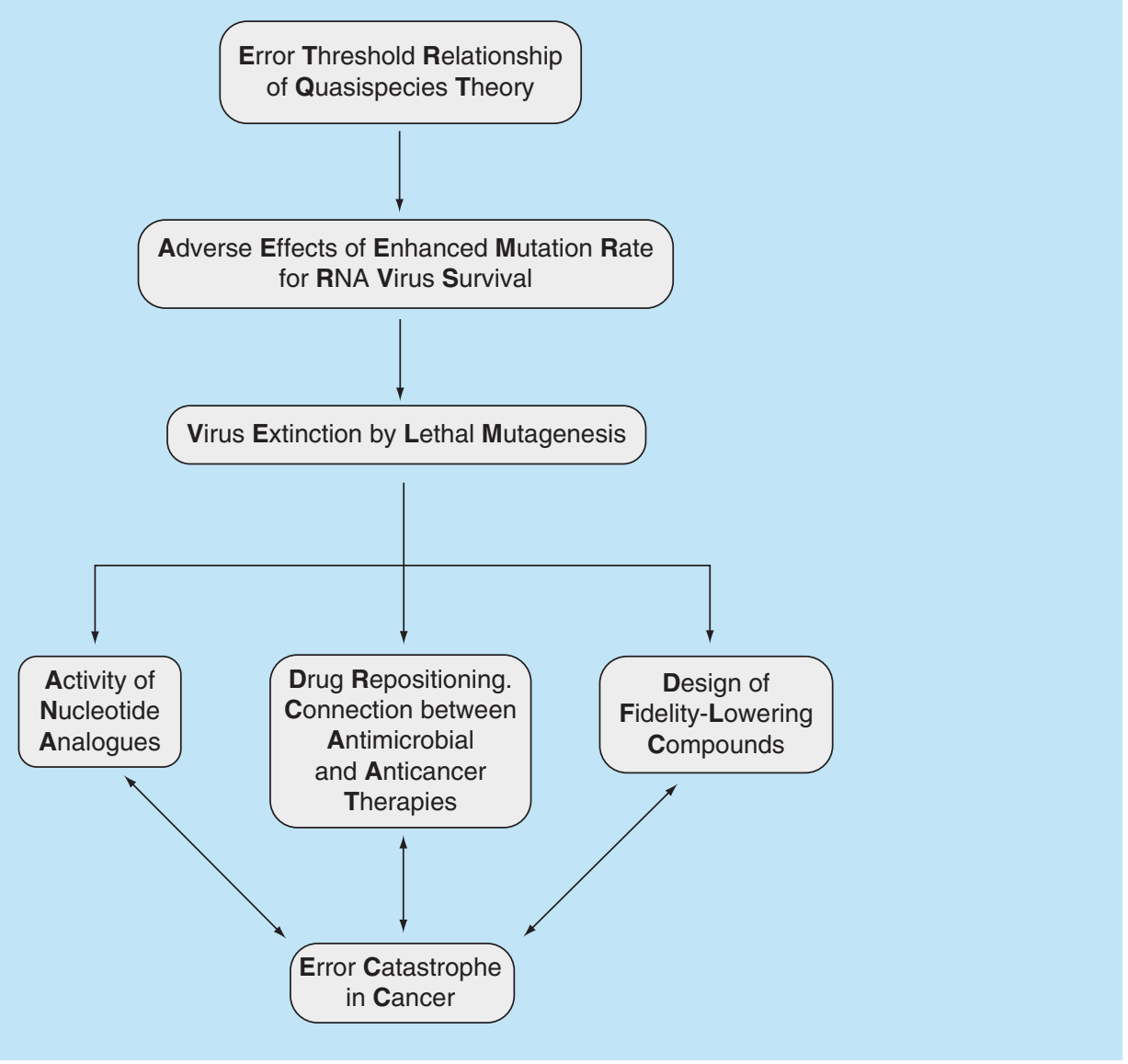

Figure 1. Flow of concepts from the error threshold relationship of quasispecies theory to lethal mutagenesis, and related issues. Justification and references are given in the text.

biology (innate immune responses, modulation of replication and virulence, and viral persistence $[31,32]$ ), a true revival of implications put forward half a century ago [33,34].

The second step is reached as mutagenesis proceeds beyond the lethal defection phase and mutations accumulate, due either to mutagenesis sustained in time or higher mutagen doses per unit time. This new stage has been termed overt lethality, and it is characterized by a larger average number of mutations per genome. Its expected occurrence, given the average deleterious effects of multiple random mutations in the same genome, was further supported by the rescue during FMDV mutagenesis of genomes that could not be viable due to critical polymerase lesions, as evidenced by biochemical and structural investigations [35]. If high mutagenic rates are reached directly, the lethal defection phase is expected to be brief or absent, and extinction to be a direct consequence of overt lethality. In the standard cell culture and in vivo scenarios, lethal defection and overt lethality probably overlap during the transition toward extinction, as suggested by isolation from FMDV on its way toward extinction of infectious biological clones that display a wide range of fitness values [36]. Given the mutant spectrum complexity of mutagenized viral populations, it is possible that additional categories of viral variants and types of intergenome interactions still to be discovered, intervene in the process of extinction. Deterioration of viral functions due to mutations is expected to occur at the RNA and protein levels, and viral protein stability may be a relevant factor [37-39].

The lethal defection-overt lethality model is not incompatible with the theoretical proposal that the loss of the master sequence generates a drifting mutant cloud that due to the advantage of genomes lying on a high fitness plateau (termed advantage of the flattest) [40,41] should not reach extinction (reviewed in [24]). From what we know of the molecular biology of RNA viruses, a drift in sequence space (without guiding selection), which from a theoretical point of view should perpetuate the mutant spectrum, would in reality provoke that genomes soon reach points of nonviability. The various theoretical arguments have had the merit of emphasizing an important 
distinction: loss of superiority of the master sequence and survival of a drifting mutant spectrum (that fits the error threshold concept of quasispecies theory) versus extinction of both the master sequence and the mutant spectrum (that fits extinction of viruses) [42]. The aim of lethal mutagenesis is extinction of both the master or dominant sequences and their surrounding mutant spectra, although the loss of master superiority by itself may be a predisposing factor to reach extinction.

Deep sequencing methodologies (that count as tens of thousands the number of genomes that can be sequenced from a viral population) have dispelled any doubts about the extreme complexity of mutant spectra of RNA viruses. Deep sequencing characterization of mutagenized RNA viruses (a type of analysis which is still in its infancy), may help elucidate the contribution of different molecular events to extinction. Despite alternative theoretical preferences, the end result is that enhanced mutagenesis, which is within reach of current pharmacology, can achieve virus extinction, and that its molecular basis is neatly distinct from that of standard inhibition of virus replication. To further address this important issue, next we briefly review studies to illustrate parameters that affect the efficacy of lethal mutagenesis, with emphasis on proofs of concept.

\section{Critical findings \& current research}

Initial work with FMDV indicated that high viral fitness and large viral population size decreased the efficacy of mutagenic agents, and delayed virus extinction, in agreement with the prediction of the error threshold relationship [23]. For high fitness FMDV and HIV-1 populations, it was necessary to combine a mutagenic agent with a nonmutagenic inhibitor to achieve extinction $[43,44]$.

A higher suppresive effect of a sequential administration of an antiviral nonmutagenic inhibitor, followed by a mutagenic agent than the converse (first a mutagenic agent and then an inhibitor) or the corresponding combination (inhibitor and mutagen-administered together) was documented with FMDV and lymphocytic choriomeningitis virus (LCMV) as model systems in cell culture. For FMDV, the advantage was shown using guanidine hydrochloride as inhibitor and FU as mutagen [45]. For LCMV, similar conclusions were reached with FU and ribavirin at concetrations at which it acts mainly as mutagen or as inhibitor [46].

The results of a preferred sequential inhibitor-mutagen administration to supress viral replication are consistent with a theoretical model of the interplay between mutagenic agents and inhibitors acting on a replicating virus, and also with the fact that absence of an inhibitor during the mutagenesis step may permit defective genomes to contribute to extinction by lethal defection [45]. These findings imply that there is still room to investigate alternative ways to administer mutagenic agents and nonmutagenic inhibitors for optimal efficacy, and this research is now in progress. In particular, no data are available in vivo. The accumulating evidence that lethal mutagenesis can be effective in plants and animals (examples in Tables $1 \& 2$ ) opens the way to studies on the efficacy of sequential versus combined administration of inhibitors and mutagens at the organism level.

Enhancement of drug resistance by high viral fitness has been recently reported with hepatitis $\mathrm{C}$ virus (HCV). Deep sequencing and genetic analyses documented that this class of drug resistance is distinct from the standard resistance profusely documented with many viruses, since it is independent of the presence of genomes harboring bonafide-resistance mutations [47,48]. The deep sequencing evidence for this fitness-dependent drug resistance was that no previously recognized resistance-associated mutations were detected in high fitness HCV populations, at least within the portion of the mutant clouds observable with current methodology. The genetic evidence was that similar levels of resistance were scored in infections over a 1000-fold range of multiplicity of infection, as well as in infections with biological clones isolated from the resistant populations $[47,48]$.

To interpret fitness-dependent drug resistance, it should be emphasized that fitness is a multifactorial parameter that has proven relevant for RNA virus-host interactions and disease processes [49-52]. The fact that high HCV fitness decreased sensitivity to all antiviral agents tested (that included mutagenic and nonmutagenic inhibitors, the latter directed to viral or cellular functions), lent to the proposal of a replicative site-drug competition model to account for the results [48]. Since fitness increase of HCV was associated with both higher replication rate and higher maximum level of progeny production [53], we suggested that a larger number of replicative site equivalents in relation to a given level of drug concentration that reaches the replication complexes, should facilitate drug escape. Support for this proposal has been recently obtained with the comparison of mutant spectrum complexity and composition of low and high fitness HCV populations subjected to favipiravir and ribavirin mutagenesis [54]. High fitness did not modify the mutational bias in favor of $\mathrm{G} \rightarrow \mathrm{A}$ and $\mathrm{C} \rightarrow \mathrm{U}$ transitions produced by favipiravir or ribavirin on HCV (other examples of mutational bias are included in Tables $1 \& 2$ ), but it limited the expansion of the mutant spectrum evoked by the mutagenic analogs. The fitness-dependent HCV response to mutagenesis is consistent 
with the replicative site-drug competition mechanism, although other, nonmutually exclusive mechanisms may also participate [54]. The results with HCV have introduced fitness as a major parameter in the response of viruses to lethal mutagenesis [54]. A derivation of the mutant spectrum analyses of $\mathrm{HCV}$ subjected to mutagenesis has been the recognition that not all parameters available to quantify the diversity of a mutant spectrum [55] are equally suited to identify and characterize a process of lethal mutagenesis. Rare haplotype load (the combination of different mutations in the same read, found at the lowest frequencies) has proven one of the most adequate parameters that should find an application to distinguish nucleotide analogs that act only as inhibitors from those that display a mutagenic activity [56].

Work with the arenavirus LCMV provided support for lethal mutagenesis in negative strand RNA viruses [57-59]. A proof of concept obtained with this virus was the demonstration that FU could prevent the establishment of a persistent LCMV infection in mice [60]. The experiments showed that the administration of a base analog could limit the progression of a viral infection in vivo. Work with LCMV indicated also a mutagenic activity of ribavirin for this important group of viral pathogens [61], and supported the possibility of sequential inhibitor-mutagen administrations for higher antiviral efficacy [46].

A pioneer clinical trial based on a lethal mutagenesis strategy involved administration of the pyrimidine analog KP-1461 (N4-heptyloxycarbonyl-5,6-dihydro-5-aza-2'-deoxycitidine), the prodrug of KP-1212 (5,6-dihydro-5aza-2'-deoxycitidine) to HIV-1-infected patients that at the time did not have other therapeutic possibilities. Although no HIV-1 extinction was achieved, the virus was mutagenized, thus documenting feasibility of lethal mutagenesis for human therapy [62]. HIV-1 and retroviruses in general are not the easiest infections to combat with mutagenic nucleotides since during the proviral step inherent to their replication cycle, the viral genetic material behaves as part of the host DNA, with the corresponding high template copying fidelity. Current efforts with new mutagenic agents [63,64], together with strategies to activate proviral DNA expression, may open possibilities of lethal mutagenesis approaches for retroviruses.

Recent salient in vivo studies with favipiravir (by Arias et al. with norovirus [65], and de Lamballerie and colleagues with Ebola virus [19], details in Table 2) have reinforced lethal mutagenesis as an antiviral design. These studies with favipiravir have followed others with ribavirin as a broad-spectrum antiviral agent, in particular as a component of the treatment for chronic HCV infection. There is a remarkable long-lasting controversy on whether ribavirin acts as a mutagen for HCV in vivo. Despite clinical evidence of mutagenesis during ribavirin monotherapy [66], and supportive phylogenetic evidence [67], the dominant mechanism of ribavirin efficacy for HCV is still an open question. The issue might be resolved soon given the benefits of including ribavirin in some new combinations of direct-acting antiviral agents, and the increasing application of deep sequencing to the characterization of HCV populations from infected patients treated with ribavirin-containing inhibitor combinations. Ultradeep sequencing has recently revealed mutagenesis of the new emergent hepatitis $\mathrm{E}$ virus by ribavirin in vivo [68]. A boost for the lethal mutagenesis field is that ribavirin, one of the most significant inhibitors in the history of antiviral pharmacology [11], may embrace mutagenesis as an ingredient of its antiviral activity.

\section{Some key features of lethal mutagenesis}

Comparison of the mutant spectra of viral populations that have multiplied in absence or presence of nucleotide analogs has suggested some features of lethal mutagenesis that can serve both to diagnose its occurrence and to inform of its molecular basis. We have identified the following: A mutagenic analog tends to enhance the mutant spectrum complexity associated with the transition toward extinction, as evidenced by molecular cloning-Sanger sequencing and deep sequencing. The increase of mutant-spectrum complexity is often (perhaps not always) accompanied of a mutational bias which tends to be typical for a given analog, but that may vary depending on the virus-host system. Documented examples are a predominance of $A \rightarrow G$ and $U \rightarrow C$ transitions evoked by $\mathrm{FU}$, and of $\mathrm{G} \rightarrow \mathrm{A}$ and $\mathrm{C} \rightarrow \mathrm{U}$ transitions evoked by favipiravir and ribavirin. Mutational spectrum biases are to be regarded only as tendencies because exceptions have been reported. As examples, favipiravir evoked a slight increase of $A \rightarrow G$ and $U \rightarrow C$ transitions in norovirus RNA [65]. Also, within the mutation detection limits imposed by molecular cloning-Sanger sequencing, no significant mutational bias was observed in preextinction FMDV populations passaged in the presence of favipiravir [69]. Statistical reinforcement provided by deep sequencing may help clarifying the extent of mutational bias evoked by different analogs, and its role in virus extinction. The transition toward extinction takes place with a significant decrease of specific infectivity (the ratio between the number of infectious units and the amount of viral RNA at a given time point) and without modification of the consensus sequence of the population [70,71]. 


\section{Table 3. Main features of lethal mutagenesis of viruses.}

- Increase of population diversity, with rare haplotype load as a diagnostic index

- Frequent mutagen-induced mutational bias, dependent on the analog and the virus-host system

- Decrease of virus-specific infectivity, the ratio between the number of infectious units and the amount of viral RNA

- Invariance of the consensus genomic sequence

$\dagger$ Points based on several investigations some of which are reviewed in the text and in Tables 1 \& 2 .

Thus, the state of the art of lethal mutagenesis has already suggested some generalizations (Table 3) that should help diagnose this mechanism of viral extinction, and distinguish it from extinction mediated solely by inhibition, in absence of mutagenesis.

\section{Conclusion: additional comments, challenges \& prospects}

The fact that lethal mutagenesis is on the way toward a therapeutic reality has come as a surprise mainly to classical pharmacology that did not count on quasispecies and its conceptual derivations as penetrating this field of medical research. Several base and nucleoside analogs once considered only inhibitors of viral replication through various biochemical and immunological mechanisms that did not imply mutagenesis, are now known to be mutagenic for several RNA viruses. Expanding on some of the issues listed in the Introduction of this article, of particular interest is a clarification of the actual contribution of the mutagenic activity per se to the antiviral efficacy. For most nucleotide analogs, mutagenesis is accompanied with other antiviral mechanisms, as amply documented in the case of ribavirin, and more recently also for favipiravir. To eliminate an array of mechanisms and potential off-target effects, and to keep mutagenesis of viral RNA as the only mode of action of a drug is not technically feasible. A related point is that a mutagenic activity should entail an inhibitory activity because of the deterioration of viral functions induced by mutagenesis. However, there might be an inhibitory activity distinct from the mutagenic activity. This is the case of ribavirin nucleotides on the HCV polymerase [72], or of FU on FMDV replication [73]. FU-monophosphate binds covalently to primer protein VPg and blocks the protein-directed initiation of RNA synthesis while the triphosphate form is incorporated during RNA elongation, thereby introducing mutations that should also result in inhibition. Thus, a current challenge is to quantify the weight of mutagenesis in the extinction process.

In view of the increasing number of viruses for which favipiravir and ribavirin have proven mutagenic, a pendent question is whether in viruses for which these analogs have been reported to be inhibitory and not mutagenic, a mutagenic activity might have been missed. Such a failure could be due to insufficient penetration into the composition of the mutant spectra, or to the time postinfection or post-treatment chosen for the analysis. When FMDV was subjected to ribavirin mutagenesis, a transient expansion was followed by a compression of the mutant spectrum [74,75]. In HCV-infected patients treated with ribavirin, early or transient increases of mutation frequency have been reported [76,77]. Also, model studies in cell culture [54] suggest that mutant spectrum expansions may be limited for high fitness $\mathrm{HCV}$, expected to be reached when the virus has undergone long-term adaptation to a human liver. To complicate matters further, the possible participation of cellular editing activities in viral mutagenesis [78], and the recognition of cell-coded antiviral ribonucleotides [79] enter the picture of lethal mutagenesis.

A potential problem to be considered is the selection of viral mutants displaying resistance to mutagenic nucleotide analogs that could jeopardize lethal mutagenesis efficacy. Resistance to mutagenic nucleotide analogs has been described, but the available data do not allow to conclude whether their frequency is as high as for standard nonmutagenic inhibitors or not. When resistance to mutagenic nucleotide analogs maps in the viral polymerase or nonstructural contact proteins it may be due to decrease of affinity for the nucleotide analog or to modulation of mutation types ([80] and references therein). Selection of nucleotide analog-resistant mutants has required serial passages under subinhibitory and sublethal concentrations of the mutagenic agent, and have not been reported during lethal mutagenesis experiments conductive to viral extinction. It is unlikey that escape mutants can be selected under uninterrupted, enhanced mutagenic activity. However, limitation of the mutagenic activity in vivo may occur as a result of virus compartmentalization into tissues or organs with limited access to the nucleotide analogs. Therefore, in vivo evaluations are necessary to monitor mutagen concentrations in the different compartments where viral replication takes place. As with standard antimicrobial treatments, lethal mutagenesis must follow the dictum 'hit early, hit hard' [81,82].

A relevant issue is the validation of a mutagenic compound as an antiviral agent by regulatory agencies such as the US FDA. Ribavirin was the FDA approved for the treatment of HCV infection and respiratory syncytial virus 
infection in children, and it is used off-label against some other viral pathogens, notably arenaviruses. Favipiravir has been licensed as an anti-influenza agent in Japan, and it has been subjected to trials against influenza infections (US NIH, identifier NCT02008344) and Ebola infections (JIKI trial, US National Institutes of Health, identifier NCT02662855). It is used off-label against several viral infections. These trials were performed (and licensing decisions taken) without knowledge of their mutagenic activity for RNA viruses. Further acceptance by the FDA (and other agencies) for a more extended usage as antiviral agents, not only off-label for life-threatening infections, would require further evaluations such as by the FDA Center for Drug Evaluation and Research. Although Phase I (Discovery and Development) have been largely completed for compounds used off-label, aspects of Phase II (Preclinical Trials), Phase III (Clinical Research), Phase IV (FDA Review) and Phase V (FDA Post-Market Safety Monitoring) may require evaluation. Accelerated approval may be justified for life-threatening infections without alternative treatment options (see https//www.fda.gov and https://www.fda.gov/Drugs/DevelopmentApprovalP rocess/default.htm\#Developing). New expected developments are: Introduction of new compounds (nucleotide analogs and other) in lethal mutagenesis protocols, either as a result of drug repositioning or synthesis of new compounds. This is an active field of research [83], expected to broaden the range of candidate molecules to be considered for lethal mutagenesis-based antiviral protocols. Additional in vivo experiments with animals and plants to explore the efficacy of lethal mutagenesis for relevant viral pathogens. Pharmacokinetic evaluations of mutagenic agents in vivo with quantifications of prodrug and active drug at relevant subcellular localizations. Relaunching of clinical trials with humans, involving administration of compounds of proven safety and efficacy in animal models; implementation of treatments in cases of life-threatening viral infections. Extensions to cellular systems such as cancer for which an error catastrophe concept has been defined [84,85]. If progress in these four points could be attained during the coming decade, with the support of theoretical models and simulation studies, a new antiviral strategy derived from the theoretical concept of quasispecies would be on its way to implementation.

\section{Future perspective}

It is likely that additional antiviral compounds are proven mutagenic for RNA viruses, thus redefining the mechanism of activity of some classic and newly developed antiviral agents. This will force reevaluation of side effects in terms of possible mutagenic activities for host cells and organisms. Until safety issues are cleared from this perspective, use of lethal mutagens may be restricted to life-threatening infections for which no alternative, effective nonmutagenic inhibitors are available. These developments should parallel basic research to optimize administration protocols in vivo to minimize dosage and maximize efficacy.

\section{Executive summary}

- Lethal mutagenesis is an active and growing field of antiviral research.

- Two major steps have been identified in the process of lethal mutagenesis: lethal defection or interference by newly generated mutants, and overt lethality due to accumulation of mutations.

- Important antiviral agents such as ribavirin and favipiravir, once considered only inhibitors, may actually exert their antiviral activity partly as mutagenic agents.

- Viral fitness can be a determinant of resistance to lethal mutagenesis, as evidenced by work with hepatitis $C$ virus.

- Sequential inhibitor-mutagenic administrations may be more effective than the corresponding combinations, and substantiation of this finding in cell culture requires in vivo evaluations.

- Extensions to anticancer therapy are among several developments that can be anticipated in this rising field of investigation.

Financial \& competing interests disclosure

C Perales is supported by the Miguel Servet program of the Instituto de Salud Carlos III (CP14/00121), cofinanced by the European Regional Development Fund (ERDF). CIBERehd (Centro de Investigación en Red de Enfermedades Hepáticas y Digestivas) is funded by Instituto de Salud Carlos III. The work in Madrid was supported by grants BFU-2011-23604, SAF2014-52400-R from Ministerio de Economía y Competitividad, SAF2017-87846-R, BFU2017-91384-EXP, PI18/00210 from Ministerio de Ciencia, Innovación y Universidades, and S2013/ABI-2906 (PLATESA from Comunidad de Madrid/FEDER) and P2018/BAA-4370 (PLATESA2 from Comunidad de Madrid/FEDER) (http://platesa-es.weebly.com). The work in Barcelona was also funded by Instituto de Salud Carlos III; by grants PI15/00829 and PI16/00337 cofinanced by the ERDF; and by CDTI (Centro para el Desarrollo Tecnológico Industrial), Spanish Ministry of Economics and Competitiveness (MINECO), IDI-20151125. Institutional grants from the Fundación Ramón 
Areces and Banco Santander to the CBMSO are also acknowledged. The authors have no other relevant affiliations or financial involvement with any organization or entity with a financial interest in or financial conflict with the subject matter or materials discussed in the manuscript apart from those disclosed.

No writing assistance was utilized in the production of this manuscript.

\section{References}

Papers of special note have been highlighted as: $\bullet$ of interest; $\bullet \bullet$ of considerable interest

1. Holland JJ, Spindler K, Horodyski F, Grabau E, Nichol S, Vandepol S. Rapid evolution of RNA genomes. Science 215(4540), 1577-1585 (1982).

-• A premonitory review of the multiple biological and medical implications of high mutation rates of RNA viruses.

2. Domingo E. RNA virus evolution and the control of viral disease. Prog. Drug Res. 33, 93-133 (1989).

3. Domingo E, Sheldon J, Perales C. Viral quasispecies evolution. Microbiol. Mol. Biol. Rev. 76(2), 159-216 (2012).

- A review of quasispecies implications for viral pathogenesis and disease control.

4. Andino R, Domingo E. Viral quasispecies. Virology 479-480 46-51 (2015).

5. Domingo E, Perales C. Quasispecies and virus. Eur. Biophys. J. 47(4), 443-457 (2018).

6. Agol VI, Gmyl AP. Emergency services of viral RNAs: repair and remodeling. Microbiol. Mol. Biol. Rev. 82(2), (2018).

- Deep penetration into molecular mechanisms of RNA variation and survival.

7. Orgel LE. The maintenance of the accuracy of protein synthesis and its relevance to ageing. Proc. Natl Acad. Sci. USA 49, 517-521 (1963).

8. Eigen M, Schuster P. The Hypercycle. A Principle of Natural Self-organization. Springer, Berlin, Germany (1979).

-. Formulation of quasispecies theory and the beginning of the quasispecies adventure in biological sciences.

9. Loeb LA, Essigmann JM, Kazazi F, Zhang J, Rose KD, Mullins JI. Lethal mutagenesis of HIV with mutagenic nucleoside analogs. Proc. Natl Acad. Sci. USA 96, 1492-1497 (1999).

- Evidence of detrimental effect of enhanced mutagenesis for HIV-1, and the coining of the term lethal mutagenesis.

10. Holland JJ, Domingo E, De La Torre JC, Steinhauer DA. Mutation frequencies at defined single codon sites in vesicular stomatitis virus and poliovirus can be increased only slightly by chemical mutagenesis. J. Virol. 64, 3960-3962 (1990).

- $\quad$ First evidence of the adverse effect of enhanced mutagenesis for RNA viruses.

11. De Clercq E, Li G. Approved antiviral drugs over the past 50 years. Clin. Microbiol. Rev. 29(3), 695-747 (2016).

12. Beaucourt $S$, Vignuzzi M. Ribavirin: a drug active against many viruses with multiple effects on virus replication and propagation. Molecular basis of ribavirin resistance. Curr. Opin. Virol. 8, 10-15 (2014).

13. Crotty S, Maag D, Arnold JJ et al. The broad-spectrum antiviral ribonucleotide, ribavirin, is an RNA virus mutagen. Nat. Med. 6, 1375-1379 (2000).

- A turning point in the understanding of nucleotide analogs as mutagenic agents for viruses.

14. Furuta $\mathrm{Y}$, Takahashi $\mathrm{K}$, Fukuda $\mathrm{Y}$ et al. In vitro and in vivo activities of anti-influenza virus compound T-705. Antimicrob. Agents Chemother. 46(4), 977-981 (2002).

15. Sangawa $\mathrm{H}$, Komeno $\mathrm{T}$, Nishikawa $\mathrm{H}$ et al. Mechanism of action of T-705 ribosyl triphosphate against influenza virus RNA polymerase. Antimicrob. Agents Chemother. 57(11), 5202-5208 (2013).

16. Jin Z, Smith LK, Rajwanshi VK, Kim B, Deval J. The ambiguous base-pairing and high substrate efficiency of T-705 (Favipiravir) ribofuranosyl 5'-triphosphate towards influenza A virus polymerase. PLoS ONE 8(7), e68347 (2013).

17. Abdelnabi R, Morais ATS, Leyssen P et al. Understanding the mechanism of the broad-spectrum antiviral activity of favipiravir (T-705): key role of the F1 motif of the viral polymerase. J. Virol. 91(12), (2017).

18. Baranovich T, Wong SS, Armstrong J et al. T-705 (favipiravir) induces lethal mutagenesis in influenza A H1N1 viruses in vitro. J. Virol. 87(7), 3741-3751 (2013)

19. Guedj J, Piorkowski G, Jacquot $\mathrm{F}$ et al. Antiviral efficacy of favipiravir against Ebola virus: a translational study in cynomolgus macaques. PLoS Med. 15(3), e1002535 (2018).

- Evidence that the beneficial effects of favipiravir to control Ebola infections may involve lethal mutagenesis.

20. Page KM, Nowak MA. A generalized adaptive dynamics framework can describe the evolutionary Ultimatum Game. J. Theor. Biol. 209(2), 173-179 (2001).

21. Swetina J, Schuster P. Self-replication with errors. A model for polynucleotide replication. Biophys. Chem. 16(4), 329-345 (1982).

22. Schuster P. Quasispecies on fitness landscapes. Domingo E, Schuster P (Eds). Curr. Top. Microbiol. Immunol. 392, 61-120 (2016).

23. Sierra S, Dávila M, Lowenstein PR, Domingo E. Response of foot-and-mouth disease virus to increased mutagenesis. Influence of viral load and fitness in loss of infectivity. J. Virol. 74, 8316-8323 (2000). 
24. Tejero H, Montero F, Nuno JC. Theories of lethal mutagenesis: from error catastrophe to lethal defection. Curr. Top. Microbiol. Immunol. 392, 161-179 (2016).

25. Bull JJ, Sanjuan R, Wilke CO. Theory of lethal mutagenesis for viruses. J. Virol. 81(6), 2930-2939 (2007).

26. Pariente N, Airaksinen A, Domingo E. Mutagenesis versus inhibition in the efficiency of extinction of foot-and-mouth disease virus. $J$. Virol. 77(12), 7131-7138 (2003).

27. Grande-Pérez A, Lazaro E, Lowenstein P, Domingo E, Manrubia SC. Suppression of viral infectivity through lethal defection. Proc. Natl Acad. Sci. USA 102(12), 4448-4452 (2005).

28. Perales C, Mateo R, Mateu MG, Domingo E. Insights into RNA virus mutant spectrum and lethal mutagenesis events: replicative interference and complementation by multiple point mutants. J. Mol. Biol. 369(4), 985-1000 (2007).

29. González-López C, Arias A, Pariente N, Gómez-Mariano G, Domingo E. Preextinction viral RNA can interfere with infectivity. J. Virol. 78(7), 3319-3324 (2004).

30. Diaz-Martinez L, Brichette-Mieg I, Pineno-Ramos A, Dominguez-Huerta G, Grande-Perez A. Lethal mutagenesis of an RNA plant virus via lethal defection. Sci. Rep. 8(1), 1444 (2018).

31. Poirier EZ, Vignuzzi M. Virus population dynamics during infection. Curr. Opin. Virol. 23, 82-87 (2017).

32. Rezelj VV, Levi LI, Vignuzzi M. The defective component of viral populations. Curr. Opin. Virol. 33, 74-80 (2018).

33. Huang AS, Baltimore D. Defective viral particles and viral disease processes. Nature 226(243), 325-327 (1970).

34. Holland JJ. Defective viral genomes. In: Virology. Fields BM, Knipe DM, Chanock RM. (Eds). Raven Press, New York, USA, 151-165 (1990).

35. Arias A, Agudo R, Ferrer-Orta C et al. Mutant viral polymerase in the transition of virus to error catastrophe identifies a critical site for RNA binding. J. Mol. Biol. 353(5), 1021-1032 (2005).

36. Arias A, De Avila AI, Sanz-Ramos M, Agudo R, Escarmis C, Domingo E. Molecular dissection of a viral quasispecies under mutagenic treatment: positive correlation between fitness loss and mutational load. J. Gen. Virol. 94(Pt 4), 817-830 (2013).

37. Chen P, Shakhnovich EI. Lethal mutagenesis in viruses and bacteria. Genetics 183(2), 639-650 (2009).

38. Bastolla U. Detecting selection on protein stability through statistical mechanical models of folding and evolution. Biomolecules 4(1), 291-314 (2014).

39. De La Higuera I, Ferrer-Orta C, De Avila AI et al. Molecular and functional bases of selection against a mutation bias in an RNA virus. Genome Biol. Evol. 9(5), 1212-1228 (2017).

40. Schuster P, Swetina J. Stationary mutant distributions and evolutionary optimization. Bull. Math. Biol. 50(6), 635-660 (1988).

41. Wilke CO, Wang JL, Ofria C, Lenski RE, Adami C. Evolution of digital organisms at high mutation rates leads to survival of the flattest. Nature 412(6844), 331-333 (2001).

42. Bull JJ, Meyers LA, Lachmann M. Quasispecies made simple. PLoS Comput. Biol. 1(6), e61 (2005).

43. Pariente N, Sierra S, Lowenstein PR, Domingo E. Efficient virus extinction by combinations of a mutagen and antiviral inhibitors. $J$. Virol. 75(20), 9723-9730 (2001).

44. Tapia N, Fernandez G, Parera $\mathrm{M}$ et al. Combination of a mutagenic agent with a reverse transcriptase inhibitor results in systematic inhibition of HIV-1 infection. Virology 338(1), 1-8 (2005).

45. Perales C, Agudo R, Tejero H, Manrubia SC, Domingo E. Potential benefits of sequential inhibitor-mutagen treatments of RNA virus infections. PLoS Pathog. 5(11), e1000658 (2009).

46. Moreno H, Grande-Perez A, Domingo E, Martín V. Arenaviruses and lethal mutagenesis. Prospects for new ribavirin-based interventions. Viruses 4(11), 2786-2805 (2012).

47. Gallego I, Sheldon J, Moreno E et al. Barrier-independent, fitness-associated differences in sofosbuvir efficacy against hepatitis $\mathrm{C}$ virus. Antimicrob. Agents Chemother. 60(6), 3786-3793 (2016).

48. Sheldon J, Beach NM, Moreno E et al. Increased replicative fitness can lead to decreased drug sensitivity of hepatitis C virus. J. Virol. 88(20), 12098-12111 (2014).

49. Domingo E, Holland JJ. RNA virus mutations and fitness for survival. Annu. Rev. Microbiol. 51, 151-178 (1997).

50. Martinez-Picado J, Martinez MA. HIV-1 reverse transcriptase inhibitor resistance mutations and fitness: a view from the clinic and $e x$ vivo. Virus Res. 134(1-2), 104-123 (2008).

51. Quiñones-Mateu ME, Arts E. Virus fitness: concept, qunatification, and application to HIV population dynamics. Curr. Top. Microbiol. Immunol. 299, 83-140 (2006).

52. Wargo AR, Kurath G. Viral fitness: definitions, measurement, and current insights. Curr. Opin. Virol. 2(5), 538-545 (2012).

53. Moreno E, Gallego I, Gregori J et al. Internal disequilibria and phenotypic diversification during replication of hepatitis $\mathrm{C}$ virus in a noncoevolving cellular environment. J. Virol. 91, e02505-16 (2017).

54. Gallego I, Gregori J, Soria ME et al. Resistance of high fitness hepatitis C virus to lethal mutagenesis. Virology 523, 100-109 (2018). 
55. Gregori J, Perales C, Rodriguez-Frias F, Esteban JI, Quer J, Domingo E. Viral quasispecies complexity measures. Virology 493, 227-237 (2016).

56. Gregori J, Soria ME, Gallego I et al. Rare haplotype load as marker for lethal mutagenesis. PLoS ONE 13(10), e0204877 (2018).

57. Grande-Pérez A, Sierra S, Castro MG, Domingo E, Lowenstein PR. Molecular indetermination in the transition to error catastrophe: systematic elimination of lymphocytic choriomeningitis virus through mutagenesis does not correlate linearly with large increases in mutant spectrum complexity. Proc. Natl Acad. Sci. USA 99(20), 12938-12943 (2002).

58. Eigen M. Error catastrophe and antiviral strategy. Proc. Natl Acad. Sci. USA 99(21), 13374-13376 (2002).

59. Grande-Perez A, Martin V, Moreno H, De La Torre JC. Arenavirus quasispecies and their biological implications. Curr. Top. Microbiol. Immunol. 392, 231-276 (2016).

60. Ruiz-Jarabo CM, Ly C, Domingo E, De La Torre JC. Lethal mutagenesis of the prototypic arenavirus lymphocytic choriomeningitis virus (LCMV). Virology 308(1), 37-47 (2003).

61. Moreno H, Gallego I, Sevilla N, De La Torre JC, Domingo E, Martin V. Ribavirin can be mutagenic for arenaviruses. J. Virol. 85(14), 7246-7255 (2011).

62. Mullins JI, Heath L, Hughes JP et al. Mutation of HIV-1 genomes in a clinical population treated with the mutagenic nucleoside KP1461. PLoS ONE 6(1), e15135 (2011).

63. Bonnac LF, Mansky LM, Patterson SE. Structure-activity relationships and design of viral mutagens and application to lethal mutagenesis. J. Med. Chem. 56(23), 9403-9414 (2013).

64. Qiu L, Patterson SE, Bonnac LF, Geraghty RJ. Nucleobases and corresponding nucleosides display potent antiviral activities against dengue virus possibly through viral lethal mutagenesis. PLoS Negl. Trop. Dis. 12(4), e0006421 (2018).

65. Arias A, Thorne L, Goodfellow I. Favipiravir elicits antiviral mutagenesis during virus replication in vivo. eLife 3, e03679 (2014).

66. Dietz J, Schelhorn SE, Fitting D et al. Deep sequencing reveals mutagenic effects of ribavirin during monotherapy of hepatitis $\mathrm{C}$ virus genotype 1-infected patients. J. Virol. 87(11), 6172-6181 (2013).

67. Cuevas JM, Gonzalez-Candelas F, Moya A, Sanjuan R. Effect of ribavirin on the mutation rate and spectrum of hepatitis C virus in vivo. J. Virol. 83(11), 5760-5764 (2009).

68. Todt D, Gisa A, Radonic A et al. In vivo evidence for ribavirin-induced mutagenesis of the hepatitis E virus genome. Gut doi:10.1136/gutjnl-2015-311000 (2016) (Epub ahead of print).

69. De Avila AI, Moreno E, Perales C, Domingo E. Favipiravir can evoke lethal mutagenesis and extinction of foot-and-mouth disease virus. Virus Res. 233, 105-112 (2017).

70. Grande-Pérez A, Gómez-Mariano G, Lowenstein PR, Domingo E. Mutagenesis-induced, large fitness variations with an invariant arenavirus consensus genomic nucleotide sequence. J. Virol. 79(16), 10451-10459 (2005).

71. González-López C, Gómez-Mariano G, Escarmís C, Domingo E. Invariant aphthovirus consensus nucleotide sequence in the transition to error catastrophe. Infect. Genet. Evol. 5, 366-374 (2005).

72. Vo NV, Young KC, Lai MMC. Mutagenic and inhibitory effects of ribavirin on hepatitis C virus RNA polymerase. Biochemistry 42(35), 10462-10471 (2003).

73. Agudo R, Arias A, Pariente $\mathrm{N}$ et al. Molecular characterization of a dual inhibitory and mutagenic activity of 5-fluorouridine triphosphate on viral RNA synthesis. Implications for lethal mutagenesis. J. Mol. Biol. 382(3), 652-666 (2008).

74. Ojosnegros S, Agudo R, Sierra M et al. Topology of evolving, mutagenized viral populations: quasispecies expansion, compression, and operation of negative selection. BMC Evol. Biol. 8, 207 (2008).

75. Perales C, Henry M, Domingo E, Wain-Hobson S, Vartanian JP. Lethal mutagenesis of foot-and-mouth disease virus involves shifts in sequence space. J. Virol. 85(23), 12227-12240 (2011).

76. Hofmann WP, Polta A, Herrmann E et al. Mutagenic effect of ribavirin on hepatitis $\mathrm{C}$ nonstructural $5 \mathrm{~B}$ quasispecies in vitro and during antiviral therapy. Gastroenterology 132(3), 921-930 (2007).

77. Lutchman G, Danehower S, Song BC et al. Mutation rate of the hepatitis C virus NS5B in patients undergoing treatment with ribavirin monotherapy. Gastroenterology 132(5), 1757-1766 (2007).

78. Venkatesan S, Rosenthal R, Kanu N et al. Perspective: APOBEC mutagenesis in drug resistance and immune escape in HIV and cancer evolution. Ann. Oncol. 29(3), 563-572 (2018).

79. Gizzi AS, Grove TL, Arnold JJ et al. A naturally occurring antiviral ribonucleotide encoded by the human genome. Nature 558(7711), 610-614 (2018).

80. Agudo R, De La Higuera I, Arias A, Grande-Perez A, Domingo E. Involvement of a joker mutation in a polymerase-independent lethal mutagenesis escape mechanism. Virology 494, 257-266 (2016).

81. Ho DD. Time to hit HIV, early and hard. N. Engl. J. Med. 333(7), 450-451 (1995).

82. Ehrlich P. Address in Pathology on Chemiotherapy. Report from the International Medical Congress, London, UK, 353-359 (1913). 
83. Iglesias LE, Lewkowicz ES, Medici R, Bianchi P, Iribarren AM. Biocatalytic approaches applied to the synthesis of nucleoside prodrugs. Biotechnol. Adv. 33(5), 412-434 (2015).

84. Loeb LA. Human cancers express mutator phenotypes: origin, consequences and targeting. Nat. Rev. Cancer 11(6), 450-457 (2011).

85. Sole RV, Deisboeck TS. An error catastrophe in cancer? J. Theor. Biol. 228(1), 47-54 (2004).

86. Lee CH, Gilbertson DL, Novella IS, Huerta R, Domingo E, Holland JJ. Negative effects of chemical mutagenesis on the adaptive behavior of vesicular stomatitis virus. J. Virol. 71(5), 3636-3640 (1997).

87. Crotty S, Cameron CE, Andino R. RNA virus error catastrophe: direct molecular test by using ribavirin. Proc. Natl Acad. Sci. USA 98(12), 6895-6900 (2001).

88. Airaksinen A, Pariente N, Menendez-Arias L, Domingo E. Curing of foot-and-mouth disease virus from persistently infected cells by ribavirin involves enhanced mutagenesis. Virology 311(2), 339-349 (2003).

89. Severson WE, Schmaljohn CS, Javadian A, Jonsson CB. Ribavirin causes error catastrophe during Hantaan virus replication. J. Virol. 77(1), 481-488 (2003).

90. Day CW, Smee DF, Julander JG, Yamshchikov VF, Sidwell RW, Morrey JD. Error-prone replication of West Nile virus caused by ribavirin. Antiviral Res. 67(1), 38-45 (2005).

91. Dapp MJ, Clouser CL, Patterson S, Mansky LM. 5-Azacytidine can induce lethal mutagenesis in human immunodeficiency virus type 1. J. Virol. 83(22), 11950-11958 (2009).

92. Perales C, Agudo R, Domingo E. Counteracting quasispecies adaptability: extinction of a ribavirin-resistant virus mutant by an alternative mutagenic treatment. PLoS ONE 4(5), e5554 (2009).

93. Dapp MJ, Holtz CM, Mansky LM. Concomitant lethal mutagenesis of human immunodeficiency virus type 1. J. Mol. Biol. 419(3-4), 158-170 (2012).

94. Ortega-Prieto AM, Sheldon J, Grande-Perez A et al. Extinction of hepatitis C virus by ribavirin in hepatoma cells involves lethal mutagenesis. PLoS ONE 8(8), e71039 (2013).

95. De Avila AI, Gallego I, Soria ME et al. Lethal mutagenesis of hepatitis C virus induced by favipiravir. PLoS ONE 11(10), e0164691 (2016).

96. Escribano-Romero E, Jimenez De Oya N, Domingo E, Saiz JC. Extinction of West Nile virus by favipiravir through lethal mutagenesis. Antimicrob. Agents Chemother. 61(11), pii:e01400-17 (2017).

97. Bassi MR, Sempere RN, Meyn P, Polacek C, Arias A. Extinction of Zika virus and Usutu virus by lethal mutagenesis reveals different patterns of sensitivity to three mutagenic drugs. Antimicrob. Agents Chemother. 62(9), (2018).

98. Goldhill $\mathrm{DH}$, Langat $\mathrm{P}$, Xie $\mathrm{H}$ et al. Determining the mutation bias of favipiravir in influenza virus using next-generation sequencing. J. Virol. 93(2), e01217-e01218 (2019). 
